\title{
The Health of India's Elderly Population: A Comparative Assessment Using Subjective and Objective Health Outcomes
}

\author{
Jane Murray Cramm ${ }^{1} \cdot$ Lisa Bornscheuer ${ }^{1}$. \\ Anna Selivanova ${ }^{1} \cdot$ Jinkook Lee $^{2}$
}

Received: 26 December 2014 / Accepted: 15 June 2015 / Published online: 24 July 2015

C The Author(s) 2015. This article is published with open access at Springerlink.com

\begin{abstract}
This study examined relationships between and predictors of objective and subjective health measures among 766 individuals aged $\geq 45$ years in India using the 2010 pilot wave of the Longitudinal Aging Study in India (LASI). Correlations between and gender differences in objective [grip strength, lung function] and subjective [selfrated health (SRH), dependence in activities of daily living (dADL)] health measures were examined. Multivariate logistic regression analyses, accounting for sample design, were conducted to identify predictors of poor health. Fewer individuals were classified as at risk according to subjective (SRH, $9 \%$; dADL, $12 \%$ ) than objective (lung function, $57 \%$; grip strength, $77 \%$ women, $87 \%$ men) indicators. Poor SRH was only weakly correlated with dADL $(r=0.103, p \leq 0.05)$ and grip strength $(r=-0.138, p \leq 0.001)$. From this study we conclude that older Indians tend to report more positive perception of health than the objective measures of health indicates, and that subjective and objective health indicators capture different aspects of health and only weakly correlated.
\end{abstract}

Keywords Grip strength · Lung function - Self-rated health · Activities of daily living · Elderly · India

\section{Introduction}

The global demographic transition that we are witnessing is caused by simultaneous trends of declining fertility rates coupled with longer life expectancies. Where

Jane Murray Cramm

cramm@bmg.eur.nl

1 Department of Health Policy \& Management (iBMG), Erasmus University Rotterdam, Oudlaan 50, 3062 PA Rotterdam, The Netherlands

2 Center for Economic \& Social Research, University of Southern California, 635 Downey Way, Suite 312, Los Angeles, CA 90089-3332, USA 
economic development - which is closely linked to these trends via channels such as advancement in medical technologies - is particularly rapid, so is population ageing (Chan 2005; Singh et al. 2013). India falls under the United Nations' definition of 'ageing' countries ${ }^{1}$ and is a prime example of a context in which morbidity and mortality patterns are changing rapidly (Bhat and Dhruvarajan 2001; Prakash 1999). India's elderly population has grown in relative and absolute terms (Bhat and Dhruvarajan 2001; Prakash 1999), and the United Nations Population Division projects that India's population ages 50 and older will reach $34 \%$ by 2050 (UN 2001). This demographic transition has important social, economic, and public health implications; one example is increased dependency ratios (Bhat and Dhruvarajan 2001; Chan 2005; Fikree and Pasha 2004).

Some of these implications are direct consequences of the epidemiological transition that takes place concurrently. India's changing health burden is characterised by the increased importance of non-communicable diseases (e.g., chronic illnesses) and social and behavioural disorders, relative to more traditional areas of health intervention that are focused on infectious diseases (Chan 2005; Johnson 2005). Efficient public health decisions require a thorough understanding of these developments, and the examination of health outcomes in ageing populations is one way of fostering this understanding. Against this background, this study aims to add to the literature examining the usefulness of different health indicators, with particular regard to self-rated and objective health measures.

\section{Literature Review}

A variety of measures have been used to examine individuals' health status. The most frequently used measures are subjective ones, such as self-rated health (SRH) and selfperceived dependence in activities of daily living (ADL), and also recently few objective measures such as grip strength and lung function gained popularity (Ziebarth 2010). SRH and grip strength are static indicators, capturing deviations from a norm perceived as healthy (Murray and Chen 1992; Ziebarth 2010).

By contrast, dependence in ADL is a functional indicator, capturing the inability to perform certain tasks. Dependence in ADL has been associated with various outcomes of interest, such as admission to retirement homes, health care utilisation, and mortality (Tsuji et al. 1994; Luppa et al. 2010; Scott et al. 1997). The measure is particularly useful for assessment of the health status of elderly populations, where prevalence rates are especially high (Wiener et al. 1990). Experience is lacking, however, in its use in the context of developing countries, such as India (Fillenbaum et al. 1999).

Grip strength has been associated with a variety of health outcomes and can be used as a proxy for overall muscle strength. Low grip strength has been found to be a consistent predictor of mobility limitations and all-cause mortality (Bohannon 2008; Metter et al. 2002; Rantanen et al. 2000; Sallinen et al. 2010). Lung function has also been found to be a predictor of all-cause mortality in both sexes and different age groups, even when adjusting for factors such as body mass index or smoking (Hole

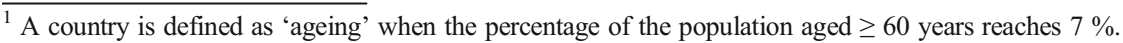


et al. 1996; Knuiman et al. 1999; Mannino et al. 2003; Neas and Schwartz 1998; Schunemann et al. 2000).

Several studies have found that subjective health measures are independent predictors of a variety of health outcomes and can thus be said to predict different 'parts' of mortality than more conventional, objective measures (Idler and Benyamini 1997). SRH, among the most frequently used measures, is an ardently debated indicator (Idler and Benyamini 1997; Johnston et al. 2009; Smith and Goldman 2011). SRH has repeatedly been proven to be a powerful and independent predictor of diverse health outcomes, and a stronger predictor of mortality than physician-assessed health as evident by a review of twenty-seven international community studies (Idler and Benyamini 1997) and empirical evidence from developed countries (Alexopoulos and Geitona 2009; Deeg and Bath 2003; Eriksson et al. 2001; McCullough and Laurenceau 2004). Even researchers who could not confirm the independent character of this predictive power, such as Bath (2003) in his study on the relationship between SRH and mortality in elderly men and women concede that differences in study design and cross-cultural variation may underlie the inconsistency of findings (Bath 2003). However, variations in the predictive ability of SRH have been found with regard to age, gender, and length of follow up (Bath 2003; Idler 2003; Jylhä 2009); for example, SRH seems to lose some predictive power in the assessment of older women's health status (Benyamini et al. 2000; Cooper et al. 2010; McCullough and Laurenceau 2004). The origin of these variations is not clear (Smith and Goldman 2011; Spiers et al. 2003); several possible explanations have been proposed, such as the greater sensitivity of SRH to certain health conditions with differing prevalence across genders (Deeg and Bath 2003; Deeg and Kriegsman 2003). Reporting bias is another issue that complicates the use of SRH (Bago d'Uva et al. 2008). For example, Lindeboom and van Doorslaer (2004) confirmed the occurrence of index and cut-point shifting for age and gender when testing for differential reporting in subjective measures such as the McMaster Health Utility Index. If the variations observed in response patterns to health surveys are systematic and related to socio-demographic differences - as they likely are - they severely hinder the correct assessment of health (Bago d'Uva et al. 2008; Sen 2002). Therefore, the state of the art allows us only to state that SRH 'clearly measure[s] something more - and something less - than objective medical ratings' (Maddox and Douglass 1973; p. 92).

Amartya Sen $(1993,2002)$ calls for further caution when using SRH in India. Sen argues that the individual's perception of health might strongly be shaped by the respective socio-economic context. Particularly, where there is an overall lack of (health) literacy - often the case in areas of poor socio-economic standing - measures of SRH might not be reliable because individuals simply fail to acknowledge certain morbidities, but perceive them to be normal. Sen's hypotheses are supported by studies such as the one conducted by Sudha et al. (2007) in South India in an elderly population, finding that marital status may bias measures of $\mathrm{SRH}$, and may do so differently across genders.

Holding against these concerns is e.g., a study conducted by Subramanian et al. (2009), that maintains that those individuals with lower SES are in fact more likely to report morbidities, even when controlling for the objective level of health. Supporting the validity of self-rated health measures are also findings from a study amongst people of 50 years or older in Bangladesh, where SRH was found to be significantly associated 
with measured physical performance, even when controlling for other factors (Rahman and Barsky 2003). Furthermore, Hirve et al. (2012) found a significant association between SRH and death independent of SES for an elderly Indian population segment. However, this study again also points to potential differences in SRH validity across genders.

The use of subjective health measures is the norm in surveys; objective measures and biomarkers are rarely used in this context. The introduction of such measures may provide an important complement to SRH and similar indicators (Ambrasat et al. 2011; Johnston et al. 2009; Kakwani et al. 1997). Thus, this study aimed to increase our understanding of health among elderly individuals in India by investigating relationships between subjective (SRH and dependence in ADL) and objective (grip strength and lung function) health indicators, and examining variation in predictor variables among health outcomes.

\section{Methods}

This study employed cross-sectional data from the 2010 pilot wave of the Longitudinal Aging Study in India (LASI), conducted in collaboration by the Harvard School of Public Health, the International Institute for Population Sciences, and the RAND Corporation. The primary objective of LASI is to provide Indian policymakers with the information needed to improve health status and health behaviour in the country's ageing population. Social, economic, and health data (e.g., income, work/employment history, SRH, blood pressure, grip strength) were collected from a nationally representative sample of the population aged $\geq 45$ years.

\section{Sample}

The LASI pilot study took place in the northern Indian states of Rajasthan and Punjab, and the southern states of Kerala and Karnataka. The sampling plan was based on the 2001 Indian census. To adequately represent different socio-economic conditions, the eight districts that served as primary sampling units were stratified across urban and rural areas. Eligible households had at least one member aged $\geq 45$ years, and eligible individuals were aged $\geq 45$ years or married to an individual of that age. A total of 1546 households was randomly sampled, and 1683 interviews were conducted in 950 of these households. The response rates were $88.5 \%$ for households and $90.9 \%$ for individuals. Within the bounds of the individual survey, grip strength, lung function, and other biomarker data were collected from a smaller sample of 928 consenting eligible individuals (interviewees and their spouses aged $\geq 45$ years) (Chien et al. 2013a, b, 2014).

\section{Outcome Measures}

\section{Self-Rated Health}

SRH was assessed by asking respondents to rate their current overall health on a fivepoint ordinal scale ranging from poor (1) to excellent (5) (full range: poor, fair, good, 
very good, excellent). This outcome variable was dichotomised as poor $(1,2)$ or good (3-5) (Chien et al. 2013a, b; Cramm and Lee 2014).

\section{Dependence in Activities of Daily Living}

Respondents' ability to perform ADL was assessed using six variables: walking across the room, dressing oneself, bathing oneself, eating, getting out of bed, and using the toilet. Each item had four possible responses indicating that the respondent had difficulty (1) or no difficulty (2) with the task, or could not (3) or did not want to (4) perform the task. Responses 1 and 3 were considered to indicate some difficulty (coded as 1), 2 was considered to indicate no difficulty (coded as 0 ), and responses of 4 were recorded as missing values.

The LASI team derived two summary ADL measures. The first measure used the ADL recommended by Wallace and Herzog (1995), including 'some difficulty' scores for the individual measures of bathing, dressing, and eating. The second summary measure additionally included getting in/out of bed and walking across the room. Summary measures were computed only for respondents with no missing value for any individual measure (Chien et al. 2013a, b). The summary variable was dichotomised as difficulty or no dependence in ADL.

\section{Grip Strength}

The LASI team measured grip strength using the sex-specific cut-off points reported by Sallinen and colleagues (2010): $21 \mathrm{~kg}$ for women (67\% sensitivity, $73 \%$ specificity) and $37 \mathrm{~kg}$ for men (62\% sensitivity, $76 \%$ specificity) (Chien et al. 2013a, b, 2014). This outcome measure was dichotomised as at risk (below cut-off value) or not at risk (cut-off value or above).

\section{Lung Function}

The LASI team used spirometry to measure lung function by examining the amount (volume) and speed (flow) of air that an individual was able to inhale or exhale. Measurement took place in the population setting. The flow electronic volume [forced expiratory volume in $1 \mathrm{~s}\left(\mathrm{FEV}_{1}\right) /$ forced vital capacity $\left.(\mathrm{FVC})\right]$ was used to identify lung problems. The criteria advanced by the Global Initiative for Chronic Obstructive Lung Disease (GOLD) were used to classify the severity of chronic obstructive pulmonary disease $\left(\mathrm{COPD}\right.$, defined as $\left.\mathrm{FEV}_{1} / \mathrm{FVC}<0.70\right)$. The severity of airflow limitation in COPD, was characterised as mild, moderate, severe, or very severe) (Chien et al. 2013a, b, 2014; Soriano et al. 2013). This health measure was dichotomised as normal or abnormal spirometry values.

\section{Socio-Demographic Measures}

The socio-demographic measures used in this research are age, marital status, educational attainment, quintiles of income, place of residence, caste, and gender. Place of residence was categorised in terms of rural/urban environment. Educational status was classified using four categories (illiterate, primary, secondary and higher education). 
Castes were classified as scheduled castes, scheduled tribes, other backward group (OBG) and non-scheduled castes or tribes. The first two categories are historically disadvantaged social classes in India (Chien et al. 2013a, b). Furthermore, the variable smoking was included in the analysis. In addition, we constructed the variable 'unhealthy environment' which takes value of 1 if there is indoor smoking at home and/or the cooking is made under chimney, the variable takes value of 0 if there is no indoor smoking and cooking is not fulfilled under chimney. In such a way it is possible to observe if lung function is associated with smoking or unhealthy smoking environment at home.

\section{Statistical Analyses}

Descriptive analyses were used to examine objective and subjective health measures. We corrected health characteristics for age-gender variations, so we used age-gender standardized values. Since we use data for elderly population (age 45 and more), age variable was split into 3 categories: age 45-60, age 60-75 and age $>75$. In addition, we used concentration curves to investigate the association between socioeconomic status and health outcomes (objective and subjective). Pearson's product-moment correlation analyses were then used to investigate relationships between these measures. Differences in health outcomes between men and women were examined using chi-squared and independent-samples $t$-tests. Multivariate logistic regression analyses were used to identify and compare predictors of poor health across genders in India's elderly population, while accounting for sample design effect.

\section{Results}

Descriptive analyses showed that the relative distributions of individual health outcomes differed between subjective and objective measures. Although $9 \%$ of respondents reported poor health and $12 \%$ reported difficulties in ADL, nearly $57 \%$ of respondents had below-normal spirometry values and the majority of respondents of both sexes ( $77 \%$ of women, $87 \%$ of men) had below-threshold grip strength values.

Tables 1 and 2 shows the descriptive statistics of health outcomes across sociodemographic characteristics among older men women in India (standardized).

Concentration curves reveal a relationship between income and health outcomes (objective and subjective) (see Graph 1).

Objective and subjective health measures showed no correlation or weak relationships. Poor health was significantly correlated with dependence in ADL $(r=0.103, p \leq$ $0.05)$ and grip strength $(r=-0.138, p \leq 0.001$; Table 3$)$.

Tables 4 and 5 present the results of multivariate logistic regression analysis of subjective and objective health indicators among men and women, respectively.

Among men, older age and being single increased the probability of being in poor health; age, educational level, income and tribe/caste/background class predicted lung function; older age and smoking increase the likelihood of dependence in ADL; educational level, income and indoor smoking predicted grip strength.

Among women, residence, age, marital status, income and indoor smoking predicted SRH; age, educational level, cooking under chimney and income predicted lung 


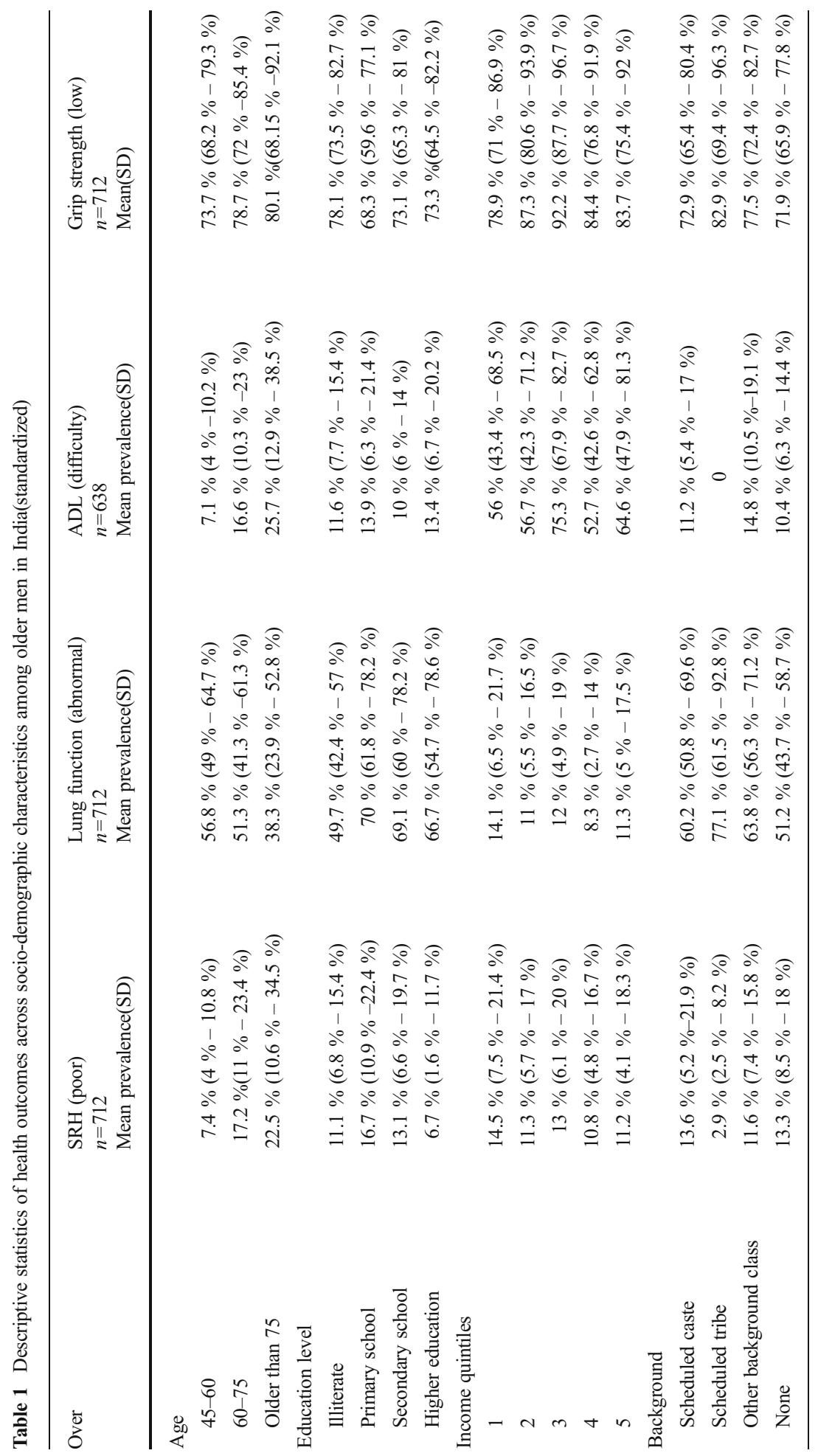




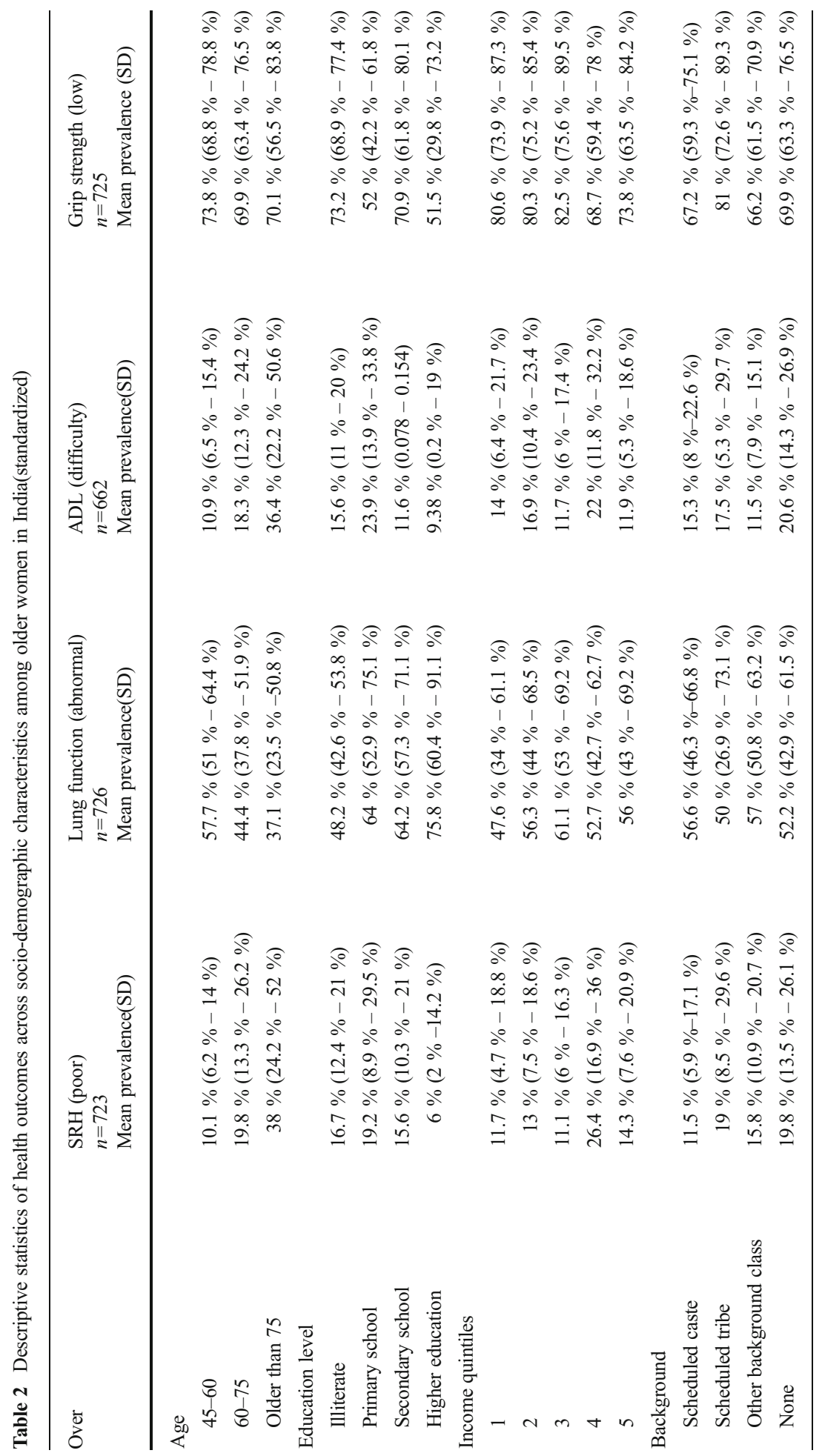



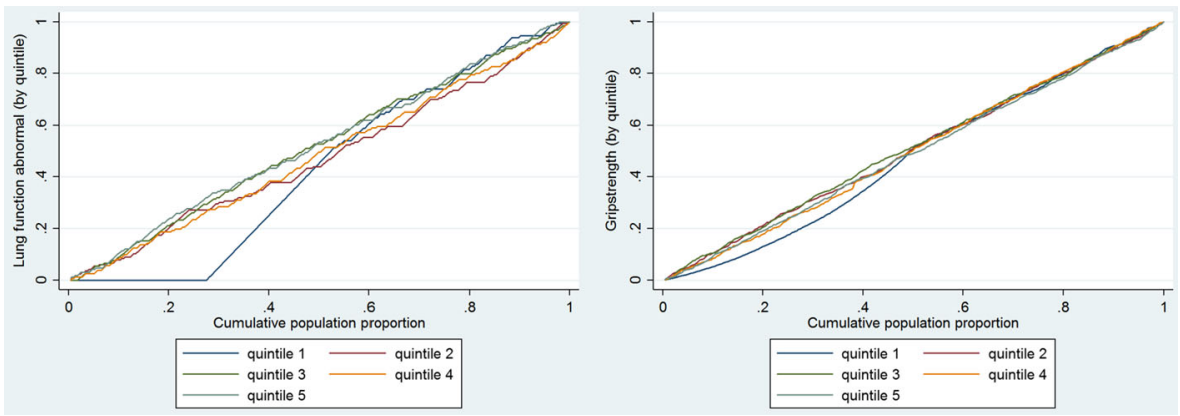

Graph 1 Cumulative population proportions

function; age, income and smoking predicted ADL; educational level and smoking predicted grip strength.

\section{Discussion}

This study added weight and detail to the findings of similar studies with the use of two objective health outcomes, as well as subjective measures, in the assessment of health in India's elderly population. The most striking finding of this study is the weakness or lack of correlation between subjective and objective health indicators. These findings were also reported by Goverover and colleagues (2005) in their study investigating the relation between subjective and objective measures of everyday life activities in persons with multiple sclerosis. They concluded that all correlations between subjective and objective functional performance measures were low and non-significant, which is consistent with other studies in among patients with MS (Hoogervorst et al. 2003; Doble et al. 1994), Alzheimer patients (Bertrand and Willis 1999) and hospitalized older patients (Sager et al. 1992). The lack of a significant relation between objective and subjective health measures suggests that they each provide unique contributions to the evaluation of health status. Self-report can provide information about a person's own perceptions regarding their health that cannot be measured using an objective assessment tool. Objective health measures are usually task oriented and are rated along a number of physical and/or cognitive dimensions enabling the observer to make a judgment as to a very specific aspect of health or health activity that can or cannot be performed independently (Gitlin 2001). As such, reliance solely on self-report health measures seem to provide information that may not reflect actual health performance

Table 3 Pearson correlations between subjective and objective health outcomes

1. Poor health (subjective)

2. Grip strength (objective)

$-0.138 * * *$

3. Dependence in ADL (subjective)

$0.103 *$

$-0.049$

4. Abnormal spirometry value (objective)

0.052

0.052

$-0.011$

$A D L$ activities of daily living. ${ }^{*} p \leq 0.05, * * * p \leq 0.001$ 


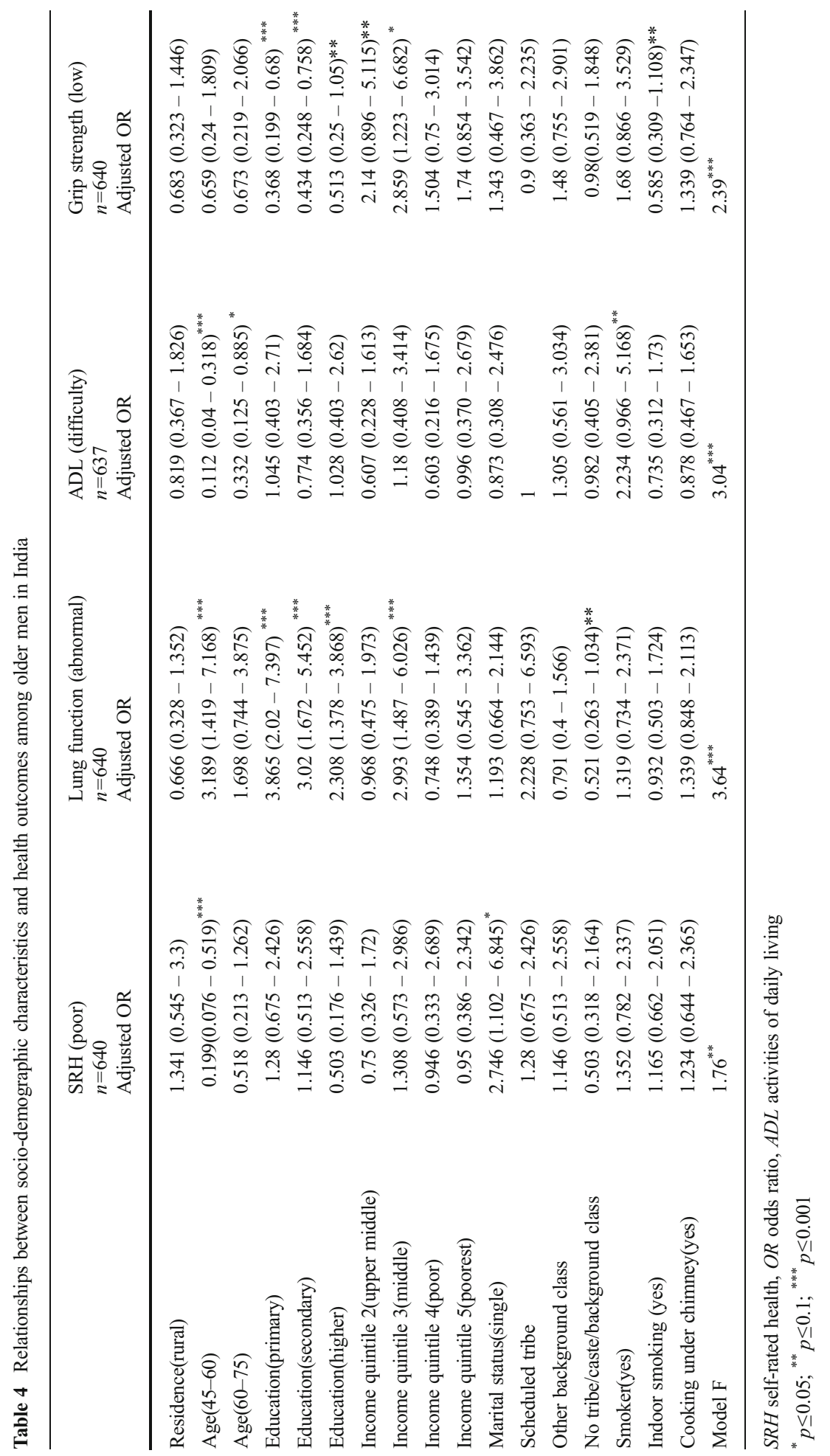




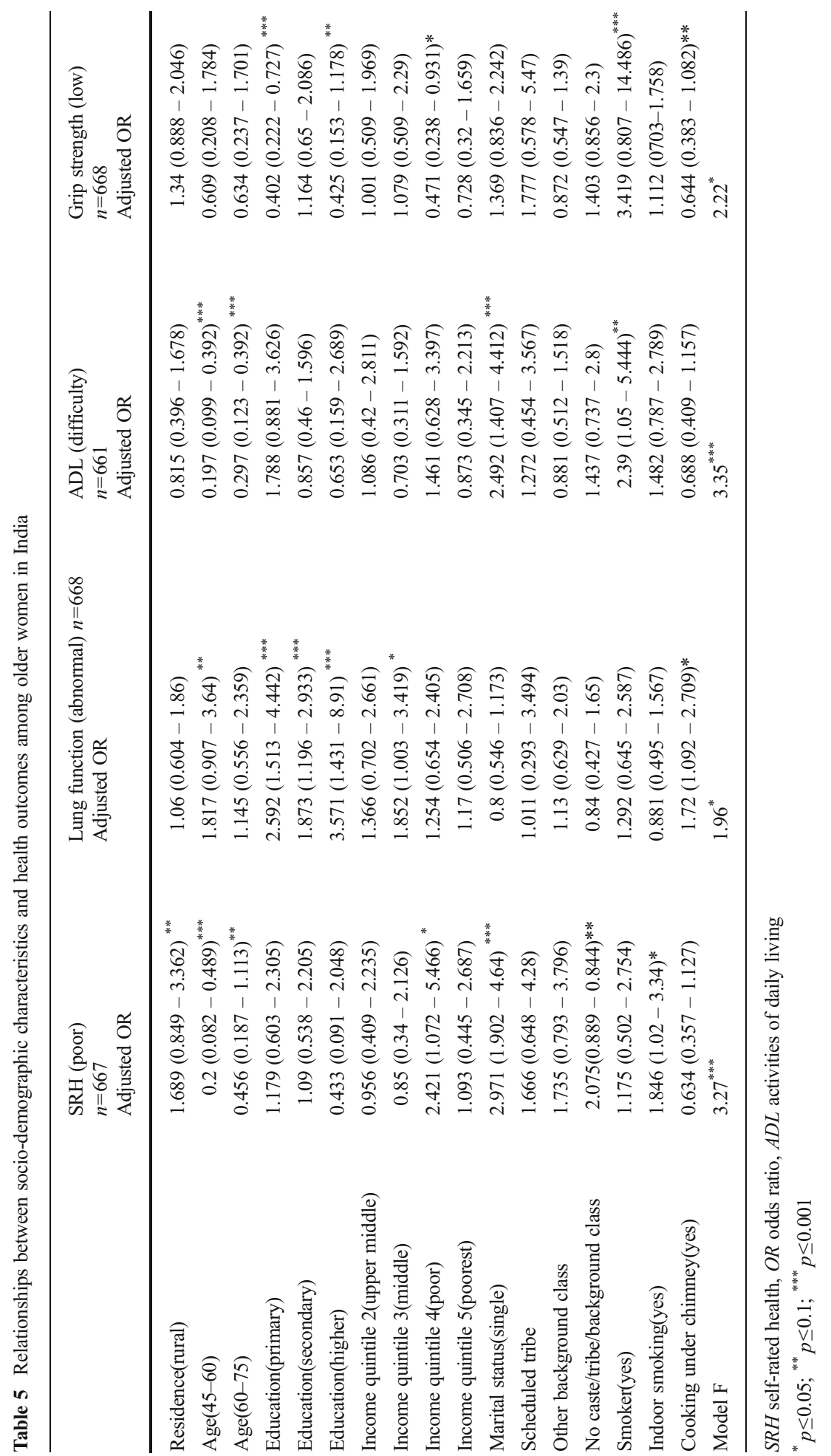


(e.g., grip strength or lung function) in everyday life (Goverover et al. 2005). Longitudinal research indeed showed that perceived or subjective health is a significant predictor of both mortality and morbidity even more so than objective health measures (Menec et al. 1999; Mossey 1995; Mossey and Shapiro 1982; Reuben et al. 1992). Furthermore, two literature reviews (Idler and Benyamini 1997) proved that subjective health remained a significant predictor of mortality, after controlling for objective health status as well as other covariates such as socioeconomic status, social support, and risk behaviours. This calls for the inclusion of both subjective as well as objective health indicators since they seem to catch 'different parts' of a person's overall health.

The limitations of this study include the cross-sectional nature of the data, which prevented the examination of causality. Furthermore, it would have been beneficial to include a measure of economic dependency in the analysis, similar to the approach taken by Roy and Chaudhuri (2008). While this study included both objective and subjective health indicators and shed some light on their (lack of) relationship there is still a lot to learn. While in line with earlier studies (Goverover et al. 2005; Hoogervorst et al. 2003; Bertrand and Willis 1999; Doble et al. 1994; Sager et al. 1992) we found that objective and subjective health indicators were not or only very weakly related to each other use of other health measures, however, might lead to different findings. Still, we believe that a strength of this study is the inclusion of subjective as well as objective indicators of health. Biomarker data collection is a valuable contribution of the LASI study, as such information - crucial for the assessment of health status - is scarce given India's poor health care infrastructure (Chien et al. 2013a, b, 2014).

In conclusion, the main contribution of this research to the existing literature is the finding that no strong relationship between the health outcomes examined persists. The disparity between the small percentages of the population classified as 'at risk' according to subjective measures, and the majority of individuals determined to be at risk according to objective indicators, suggests that they reflect different 'parts' of mortality and morbidity. While ADL or SRH is expected to be low in our study sample the high proportion of older people in India with low grip strength and poor lung function is a concern. Further study is thus warranted to obtain a full understanding of the correct application and interpretation of different health indicators depending on the problem of interest, the context in which it is investigated, and the population involved.

\section{Conflict of interest No conflict of interest.}

Open Access This article is distributed under the terms of the Creative Commons Attribution 4.0 International License (http://creativecommons.org/licenses/by/4.0/), which permits unrestricted use, distribution, and reproduction in any medium, provided you give appropriate credit to the original author(s) and the source, provide a link to the Creative Commons license, and indicate if changes were made.

\section{References}

Alexopoulos, E. C., \& Geitona, M. (2009). Self-rated health: inequalities and potential determinants. International Journal of Environmental Research and Public Health, 6(9), 2456-2469. 
Ambrasat, J., Schupp, J., \& Wagner, G. G. (2011). Comparing the predictive power of subjective and objective health indicators: changes in handgrip strength and overall satisfaction with life as predictors of mortality. SOEPpapers on Multidisciplinary Panel Data Research, 398.

Bago d'Uva, T., Van Doorslaer, E., Lindeboom, M., \& O’Donnell, O. (2008). Does reporting heterogeneity bias the measurement of health disparities? Health Economics, 17(3), 351-375.

Bath, P. A. (2003). Differences between older men and women in the self-rated health-mortality relationship. The Gerontologist, 43(3), 387-395.

Benyamini, Y., Leventhal, E. A., \& Leventhal, H. (2000). Gender differences in processing information for making self-assessments of health. Psychosomatic Medicine, 62(3), 354-364.

Bertrand, R. M., \& Willis, S. L. (1999). Everyday problem solving in Alzheimer's patients (a comparison of subjective and objective assessments). Aging \& Mental Health, 3, 281-293.

Bhat, A. K., \& Dhruvarajan, R. (2001). Ageing in India: drifting intergenerational relations, challenges and options. Ageing and Society, 21(5), 621-640.

Bohannon, R. W. (2008). Hand-grip dynamometry predicts future outcomes in aging adults. Journal of Geriatric Physical Therapy, 31(1), 3-10.

Chan, A. (2005). Aging in southeast and east Asia: issues and policy directions. Journal of Cross-Cultural Gerontology, 20(4), 269-284.

Chien, S., Feeney, K., \& Lee, J. (2013a). Longitudinal aging study in India: User guide for pilot data. RAND Labor and Population working paper series.

Chien, S., Feeney, K., \& Lee, J. (2013b). Harmonized LASI pilot data documentation: Version A. RAND Labor \& Population.

Chien, S., Feeney, K., \& Lee, J. (2014). Longitudinal aging study in India: Pilot biomarker data documentation. RAND

Cooper, R., Kuh, D., Hardy, R., FALCon Study Team, FALCon and HALCyon Study Teams, on behalf of the FALCon and HALCyon study teams, \& HALCyon Study Team \& Mortality Review Group. (2010). Objectively measured physical capability levels and mortality: systematic review and meta-analysis. $B M J$ Clinical Research, 341(7774), c4467.

Cramm, J. M., \& Lee, J. (2014). Smoking, physical activity and healthy aging in India. BMC Public Health, $14(1), 526$.

Deeg, D. J. H., \& Bath, P. A. (2003). Self-rated health, gender, and mortality in older persons: introduction to a special section. The Gerontologist, 43(3), 369-371.

Deeg, D. J., \& Kriegsman, D. M. (2003). Concepts of self-rated health: specifying the gender difference in mortality risk. The Gerontologist, 43(3), 376-386.

Doble, S. E., Fisk, J. D., Fisher, A. G., Ritvo, P. G., \& Murray, T. J. (1994). Functional competence of community-dwelling persons with multiple sclerosis using the assessment of motor and process skills. Archives of Physical Medicine and Rehabilitation, 83, 1070-1079.

Eriksson, I., Undén, A. L., \& Elofsson, S. (2001). Self-rated health. Comparisons between three different measures. Results from a population study. International Journal of Epidemiology, 30(2), 326-333.

Fikree, F. F., \& Pasha, O. (2004). Role of gender in health disparity: The South Asian context. England: BMJ Publishing Group.

Fillenbaum, G. G., Chandra, V., Ganguli, M., Pandav, R., Gilby, J. E., Seaberg, E. C., Belle, S., Baker, C., Echement, D. A., \& Nath, L. M. (1999). Development of an activities of daily living scale to screen for dementia in an illiterate rural older population in India. Age and Ageing, 28(2), 161-168.

Goverover, Y., Kalmar, J., Gaudino-Goering, E., Shawaryn, M., Moore, N. B., Halper, J., \& DeLuca, J. (2005). The relation between subjective and objective measures of everyday life activities in persons with multiple sclerosis. Archives of Physical Medicine and Rehabilitation, 86(12), 2303-2308.

Griffith, K. A., Sherrill, D. L., Siegel, E. M., Manolio, T. A., Bonekat, H. W., \& Enright, P. L. (2001). Predictors of loss of lung function in the elderly: the cardiovascular health study. American Journal of Respiratory and Critical Care Medicine, 163(1), 61-68.

Hirve, et al. (2012). Does self-rated health predict death in adults aged 50 years and above in India? Evidence from a rural population under health and demographic surveillance. International Journal of Epidemiology, 41, 1719-1727.

Hole, D. J., Watt, G. C., Davey-Smith, G., Hart, C. L., Gillis, C. R., \& Hawthorne, V. M. (1996). Impaired lung function and mortality risk in men and women: findings from the Renfrew and Paisley prospective population study. BMJ Clinical Research, 313(7059), 711-715

(discussion 715-716).

Hoogervorst, E. L., Eikelenboom, M. J., Uitdehaag, B. M., \& Polman, C. H. (2003). One year changes in disability in multiple sclerosis (neurological examination compared with patient self-report). Journal of Neurology, Neurosurgery, and Psychiatry, 74, 439-442. 
Idler, E. L. (2003). Discussion: gender differences in self-rated health, in mortality, and in the relationship between the two. The Gerontologist, 43(3), 372-375.

Idler, E. L., \& Benyamini, Y. (1997). Self-rated health and mortality: a review of twenty-seven community studies. Journal of Health and Social Behavior, 38(1), 21-37.

Johnson, M. L. (Ed.), in association with V. L. Bengtson, P. G. Coleman, and T. B .L. Kirkwood (2005). The Cambridge handbook of age and ageing. Cambridge: Cambridge University Press.

Johnston, D. W., Propper, C., \& Shields, M. A. (2009). Comparing subjective and objective measures of health: evidence from hypertension for the income/health gradient. Journal of Health Economics, 28(3), 540-552.

Jylhä, M. (2009). What is self-rated health and why does it predict mortality? Towards a unified conceptual model. Social Science \& Medicine, 69(3), 307-316.

Kakwani, N., Wagstaff, A., \& Van Doorslaer, E. (1997). Socioeconomic inequalities in health: measurement, computation, and statistical inference. Journal of Econometrics, 77(1), 87-103.

Knuiman, M. W., James, A. L., Divitini, M. L., Ryan, G., Bartholomew, H. C., \& Musk, A. (1999). Lung function, respiratory symptoms, and mortality: results from the Busselton Health Study. Annals of Epidemiology, 9(5), 297-306.

Lindeboom, M., \& Van Doorslaer, E. (2004). Cut-point shift and index shift in self-reported health. Journal of Health Economics, 23(6), 1083-1099.

Luppa, et al. (2010). Prediction of institutionalization in the elderly. A systematic review. Age and Ageing, 39, 31-38.

Maddox, G. L., \& Douglass, E. B. (1973). Self-assessment of health: a longitudinal study of elderly subjects. Journal of Health and Social Behavior, 14(1), 87-93.

Mannino, D. M., Buist, A. S., Petty, T. L., Enright, P. L., \& Redd, S. C. (2003). Lung function and mortality in the United States: data from the first national health and nutrition examination survey follow up study. Thorax, 58(5), 388-393.

McCullough, M. E., \& Laurenceau, J. (2004). Gender and the natural history of self-rated health: a 59-year longitudinal study. Health Psychology, 23(6), 651-655.

Menec, V. H., Chipperfield, J. G., \& Perry, R. P. (1999). Self-perceptions of health: a prospective analysis of mortality, control, and health. Journals of Gerontology: Biological Sciences \& Medical Sciences, 54B, 85-93.

Metter, E. J., Talbot, L. A., Schrager, M., \& Conwit, R. (2002). Skeletal muscle strength as a predictor of allcause mortality in healthy men. The Journals of Gerontology. Series A, Biological Sciences and Medical Sciences, 57(10), B359-B365.

Mossey, J. M. (1995). Importance of self-perceptions for health status among older persons. In M. Gatz (Ed.), Emerging issues in mental health and aging (pp. 124-162). Washington, D.C: American Psychological Association.

Mossey, J. M., \& Shapiro, E. (1982). Self-rated health: a predictor of mortality among the elderly. American Journal of Public Health, 72, 800-808.

Murray, C. J., \& Chen, L. C. (1992). Understanding morbidity change. The Population and Development Review, 481-503.

Neas, L. M., \& Schwartz, J. (1998). Pulmonary function levels as predictors of mortality in a national sample of US adults. American Journal of Epidemiology, 147(11), 1011-1018.

Prakash, I. J. (1999). Ageing in India. Prepared for the World Health Organization. http://www.popbook.com/ en/in/pdf/ageinginindia.pdf.

Rahman, M. O., \& Barsky, A. J. (2003). Self-reported health among older Bangladeshis: how good a health indicator is it? Gerontologist, 43(6), 856-863.

Rantanen, T., Harris, T., Leveille, S. G., Visser, M., Foley, D., Masaki, K., et al. (2000). Muscle strength and body mass index as long-term predictors of mortality in initially healthy men. The Journals of Gerontology. Series A, Biological Sciences and Medical Sciences, 55(3), M168-M173.

Reuben, D. B., Siu, A. L., \& Kimpau, S. (1992). The predictive validity of self-report and performance-based measures of function and health. Journal of Gerontology: Medical Sciences, 47, M106-M110.

Roy, K., \& Chaudhuri, A. (2008). Influence of socioeconomic status, wealth and financial empowerment on gender differences in health and healthcare utilization in later life: evidence from India. Social Science \& Medicine, 66(9), 1951-1962.

Sager, M. A., Dunham, N. C., Schwantes, A., Mecum, L., Halverson, K., \& Harlowe, D. (1992). Measurement of activities of daily living in hospitalized elderly (a comparison of self-report and performance-based methods). Journal of American Geriatrics Society, 40, 457-462. 
Sallinen, J., Stenholm, S., Rantanen, T., Heliövaara, M., Sainio, P., \& Koskinen, S. (2010). Hand-grip strength cut points to screen older persons at risk for mobility limitation. Journal of the American Geriatrics Society, 58(9), 1721-1726.

Schunemann, H. J., Dorn, J., Grant, B. J., Winkelstein, W., \& Trevisan, M. (2000). Pulmonary function is a long-term predictor of mortality in the general population: 29-year follow-up of the Buffalo Health Study. CHEST Journal, 118(3), 656-664.

Scott, W., Macera, C., Cornman, C., \& Sharpe, P. (1997). Functional health status as predictor of mortality in men and women over 65. Journal of Clinical Epidemiology, 50(3), 291-296.

Sen, A. (1993). Positional objectivity. Philosophy and Public Affairs, 22, 126-145.

Sen, A. (2002). Health: perception versus observation. British Medical Journal, 324(7342), 860-861.

Singh, L., Arokiasamy, P., Singh, P. K., \& Rai, R. K. (2013). Determinants of gender differences in self-rated health among older population: evidence From India. SAGE Open, 3, 1-12.

Smith, K. V., \& Goldman, N. (2011). Measuring health status: self-, interviewer, and physician reports of overall health. Journal of Aging and Health, 23(2), 242-266.

Soriano, J. B., Alfageme, I., Almagro, P., Casanova, C., Esteban, C., Soler-Cataluña, J. J., de Torres, J. P., Martinez-Camblor, P., Miravitlles, M., \& Celli, B. R. (2013). Distribution and prognostic validity of the new global initiative for chronic obstructive lung disease grading classification new GOLD COPD grading. CHEST Journal, 143(3), 694-702.

Spiers, N., Jagger, C., Clarke, M., \& Arthur, A. (2003). Are gender differences in the relationship between self-rated health and mortality enduring? Results from three birth cohorts in Melton Mowbray, United Kingdom. The Gerontologist, 43(3), 406-411.

Subramanian, S. V., Subramanyam, M., Selvaraj, S., \& Kawachi, I. (2009). Are self-reports of health and morbidities in developing countries misleading? Evidence from India. Social Science \& Medicine, 68(2), 260-265.

Sudha et al. (2007). Marital Status, Family Ties, and Self-rated Health Among Elders in South India. Journal of Cross Cultural Gerontology, 21 (3-4).

Tsuji, et al. (1994). The predictive power of self-rated health, activities of daily living and ambulatory activity for cause specific mortality among the elderly: a three-year follow-up in urban Japan. Journal of American Geriatrics Society, 42(2), 153-156.

United Nations, Department of Economic and Social Affairs, Population Division (2001). World Population Ageing: 1950-2050, 271.

Wallace, R. B., \& Herzog, A. R. (1995). Overview of the health measures in the Health and Retirement Study. Journal of Human Resources, 84-107.

Wiener, J. M., Hanley, R. J., Clark, R., \& Van Nostrand, J. F. (1990). Measuring the activities of daily living: comparisons across national surveys. Journal of Gerontology, 45(6), S229-S237.

Ziebarth, N. (2010). Measurement of health, health inequality, and reporting heterogeneity. Social Science \& Medicine, 71(1), 116-124. 